\title{
DEMOCRACIA Y DILEMA EFICIENCIA-EQUIDAD EN LA DESCENTRALIZACIÓN LOCAL EN VENEZUELA*
}

\author{
María Pilar García-Guadilla***
}

\section{INTRODUCCIÓN Y OBJETIVOS}

En los países que atraviesan por profundas crisis de carácter político y económico como lo es el caso de América Latina, la descentralización ha tendido a convertirse en la panacea para resolver los problemas de eficiencia del Estado, las demandas por una mayor participación y profundización de la democracia, los problemas asociados con la deslegitimación de los actores políticos e incluso, las crecientes dificultades de gobernabilidad de los sistemas políticos. Desde hace casi dos décadas y coincidiendo con la crisis económica y política de la región, muchos de los países de América Latina, entre los que se destacan Colombia, Chile, Argentina, Brasil, Costa Rica y Venezuela, han adoptado estrategias de descentralización incorporando uno o varios de los objetivos señalados anteriormente.

La descentralización puede entenderse como "el proceso mediante el cual se transfieren competencias y poder político desde el Gobierno central a instancias del Estado cercanas a la población, dotadas de independencia administrativa y legitimidad política propia, a fin de que, con la participación popular, se mejore la producción de bienes y servicios". (Córdova Macias y Ortega Hegg, 1997, pp 85. 87). Se trata de un proceso de transición hacia la democracia que debe conllevar la transformación de las relaciones de poder entre el Estado y el resto de los actores sociopolíticos; además, se caracteriza por la institucionalización de la política de participación ciudadana que debe ser el resultado del proceso de negociación entre los distintos actores sociopolíticos y exige coordinación para que se optimice la eficiencia.

Uno de los objetivos explícitos del discurso de la descentralización es el logro de una mayor eficiencia y efectividad en la prestación de los servicios estatales en todos los niveles. Dicha eficiencia debe tomar en cuenta la participación ciudadana puesto que la sociedad civil al convertirse en elector supuestamente contribuye a contrarrestar el clientelismo y otras prácticas no deseadas de los gobernantes electos'.

Sin embargo, a lo largo del análisis de los diferentes procesos de descentralización de América Latina, se han señalado las dificultades para combinar el objetivo de la eficiencia económica con el de la profundización de la democracia donde se incluye tanto la equidad social como la participación en el proceso de toma de decisiones (Borja, 1988; Coraggio, 1994; García-Guadilla, 1998). Algunos analistas destacan que dichos objetivos tienden a colidir porque la participación tiende a alargar los lapsos de decisión y por ende, encarece las políticas. Además, la imposición de una racionalidad económica para lograr la eficiencia puede contribuir a agudizar las desigualdades sociales y a excluir a sectores amplios de la población. Frente a esta posición, otros autores resaltan que si se utiliza una acepción mas amplia de eficiencia que trascienda lo económico y que incluya la eficiencia política con el objetivo de aumentar la legitimidad y la eficiencia social que tiene como objetivo la redistribución de recursos para reducir la pobreza y la desigualdad social (Campbell et al., 1991), la participación es una forma mas racional y, por lo tanto, eficiente de identificar con mayor precisión las demandas y de tomar decisiones porque permite vincular más estrechamente dichas demandas con las políticas.

Dentro de esta discusión, el objetivo de este trabajo es el de analizar si la relación entre la eficiencia y la democracia participativa es de carácter antagónico o complementario. Con este fin, se estudiará la manera en que se han combinado estos dos objetivos de la descentralización en Venezuela y mas concretamente en los municipios de Chacao, El Hatillo, Baruta, Libertador y Caroní. Una de las premisas del trabajo es que, dentro del marco jurídico de descentralización local existente en Venezuela, la preeminencia de una u otra de las dimensiones de la eficiencia (económica, política, social ) y la compatibilidad o discrepancia entre ellas dependen de varios factores que pueden combinarse de diferentes formas segun las características de cada municipio: a) el acceso a recursos económicos para atender las demandas, b) los niveles de pobreza y desigualdad que existan en el

Presentado en el XXI Internacional Congress of the Latin American Studies Association (LASA), Palmer House, Chicago, Illinois, USA. September 24-26, 1998.

Profesora e investigadora, Departamento de Planificación Urbana, Universidad Simón Bolívar, Caracas, Venezuela. e-mail:mpgarcia@usb.ve.

1. Se ha señalado que si bien la descentralización puede darse dentro de regímenes no democráticos (como lo fue el caso chileno bajo el régimen autoritario de Pinochet), la democracia participativa aseguraría un mayor nivel de gobernabilidad y de equidad). 
municipio, c) el estilo de gerencia que se privilegie en la gestión (técnico, político o mixto), c) la concepción de ciudadanía que detentan los actores sociopolíticos locales acerca de su participación en la gestión local, y d) las posibles deformaciones (clientelismos y populismo) que pueden introducirse en los procesos de participación y negociación de los recursos escasos.

La información y datos de este trabajo proceden de diversas fuentes entre las que se destacan: la aplicación de una entrevista semiestructurada a los alcaldes y los concejales de los municipios identificados anteriormente; el levantamiento de una encuesta a las asociaciones de vecinos; el análisis documental de los informes anuales, boletines y otras fuentes; y finalmente, la revisión hemerográfica de los periódicos nacionales El Universal y El Nacional durante el período 1992-1997. Dado que este trabajo forma parte de un proyecto de investigación en curso donde se incluye una muestra tipológica de los diferentes municipios de Venezuela, creeemos que su valor principal se encuentra en la posibilidad de delinear un conjunto de hipótesis alrededor de la relación eficiencia-democracia.

\section{EL DILEMA EFICIENCIA-EQUIDAD-PARTICI- PACIÓN}

\section{Eficiencia-equidad}

La eficiencia a nivel local envuelve al menos dos dimensiones: la económica y la política. La eficiencia económica tiene que ver con los costos de producción y la calidad de los servicios de infraestructura de red y sociales que, por lo general, constituyen demandas prioritarias de la población a nivel local. La eficiencia política significa el dar respuestas satisfactorias a las demandas planteadas por los electores para lograr legitimidad.

Dados los altos índices de pobreza y desigualdad social que existen en los países de América Latina, la eficiencia política tiene como requisito la eficiencia social o equidad. La equidad o eficiencia social puede ser interpretada de dos formas: reducción de los niveles de pobreza y acceso a los servicios básicos de red y sociales (Campbel et al., 1991) y participación en el proceso de toma de decisiones (Borja, 1988; Jelín, 1993). Dentro de la primera connotación, la descentralización representa una respuesta a los crecientes niveles de pobreza y desigualdad social en la distribución de los recursos con el fin de reducir la conflictividad social; la segunda acepción incluye la participación de los actores sociopolíticos locales en el proceso de tomar decisiones, lo cual supone la profundización de la democracia y la participación ${ }^{2}$.

La eficiencia social o equidad forma parte del ámbito de lo político ya que supone la decisión de prioridades dentro del proceso de toma de decisiones que afectan a la colectividad. Por lo tanto, tiene como requisito la eficiencia electoral, es decir, la existencia de mecanismos electorales que faciliten la expresión de las demandas y de las posibles soluciones por parte de los electores. En la mayoría de los países latinoamericanos que han atravesado por procesos de descentralización, las leyes electorales y las normativas existentes no garantizan la expresión de la demandas o el crite- rio de eficiencia electoral; además, las expectativas de los electores tienen a estar por encima de la realidad de los presupuestos asignados a nivel local ${ }^{3}$.

En otras ocasiones, sin embargo, el problema no es el sistema de información acerca de las demandas, sino la forma en que éstas se procesan, la cual tiende hacia un estilo clientelar que resta eficiencia y equidad a las políticas. De hecho, estas prácticas clientelares son frecuentemente utilizadas no solo por individuos particulares en su relación con los representantes electos de los partidos políticos, sino también por las asociaciones de vecinos; se trata de un nuevo clientelismo (García-Guadilla, 1998).

\section{Participación-eficiencia}

Uno de los requisitos necesarios para que se de la eficiencia ligada a la equidad, es decir, la correspondencia entre las prioridades en la alocación de recursos y las demandas, es la participación de la población en la información, en el proceso de decidir tales prioridades y en la evaluación o rendición de cuentas (García-Guadilla, 1989). No obstante, para lograr este tipo de participación es preciso partir de una concepción de ciudadanía que reconozca que la participación en la toma de decisiones sobre recursos escasos es parte del proceso de profundización de la democracia (GarcíaGuadilla y Guardía 1998).

Con relación a las vinculaciones entre participación y eficiencia es preciso destacar que, si bien en el pasado algunos autores y organismos internacionales (Freire 1973; Korten 1980; Briscoe y de Ferranti 1988; Finsterbusch and Van Wicklin III 1987; UNDP 1993; World Bank 1991) encontraron que la participación de los beneficiarios en proyectos de desarrollo mejoraba la eficiencia del mismo, esta relación causa-efecto fue cuestionada debido a lo limitado de los estudios de casos sobre los que se basaba ${ }^{4}$. No obstante, estudios adicionales donde se intentaron controlar estos factores (Narayan, 1995; Ishlam, 1995) reiteraron que la mayor participación contribuye a mejorar el desempeño de la eficiencia.

Los nuevos estudios, si bien fueron mas exhaustivos, dejan varios interrogantes sin responder, tales como: a) ¿el mejoramiento en el desempeño de los proyectos estudiados mediante estudio de casos se puede generalizar a todo tipo de proyectos o ello depende de las características del

2. La revisión sobre varias experiencias de descentralización que hizo Campbell et al. (1991) demostró que la descentralización tiende a aumentar los costos de inversión del gobierno central debido a que a las transferencias de la descentralización se agregan los costos del gobierno central. Sin embargo, este aumento de los costos no necesariamente implica una reducción de la eficiencia social o de la equidad (en la alocación de los recursos).

3. Cuando las demandas y expectativas quedan insatisfechas, se tiende a culpar a las burocracias del fracaso. Si bien una manera de contrarrestar este problema pudiera ser a través de las consultas a la población mediante encuestas y otros mecanismos de participación en la expresion de sus demandas, estos mecanismos tienen también un alto costo económico.

4. Además de lo limitado del número de casos, existen dificultades para medir estadísticamente estas variables y el posible efecto de interacción que pudiera resultar de un buen desempeño del proyecto como estímulo a la participación. 
mismo? ${ }^{5}$, b) ¿qué tipo de política favorece el logro de la mayor participación?, c) ¿se justifica la participación, incluso si ésta aumenta los costos del proyecto lo que significa que se reduce la eficiencia económica, y d) ¿puede la participación resolver el problema de que la solución propuesta no siempre sea la más eficiente?

Diversos autores utilizan definiciones distintas de la participación, las cuales van desde la participación en el proceso de información hasta la participación en la evaluación del proyecto mediante la rendición de cuentas, pasando por la participación en la decisión e instrumentación del proyecto en cuestión. Sin embargo, un grupo de estos autores entre los que se encuentran Borja (1988), Coraggio (1994), GarcíaGuadilla (1989), Restrepo (1997) y Jelín (1993) coinciden en que solo la participación que se refiere al proceso de toma de decisiones debe considerarse como tal pues es la única que sirve para profundizar los procesos de democratización. En contraste, se observa que en la mayoría de los procesos de descentralización que existen en América Latina, la participación de los actores sociales en el gobierno local es de carácter instrumental y que no existe, o es muy reducida, la participación en el proceso de toma de decisiones.

Otro de los aspectos a ser considerados es que la incorporación dentro del proceso de participación de un número mayor de actores con intereses heterogéneos puede dificultar los procesos de negociación y, por ende, aumentar los costos económicos asociados a la definición de políticas. Cunill (1997) ha señalado que la participación es "costosa" en términos del tiempo que debe de destinarse a la misma; además, se requiere de formas organizativas o de un capital social que no siempre existen. No obstante, la participación entendida bien sea como la influencia en el control de los políticos y de sus decisiones o como la incorporación al proceso de desarrollo de las políticas públicas es consustancial a la democracia: a mayor participación en el proceso de toma de decisiones, mayor democracia.

\section{Ciudadanía-participación-eficiencia}

La concepción de ciudadanía más acorde con la noción de eficiencia social o equidad implica "una práctica conflictiva vinculada al poder, que refleja las luchas acerca de quiénes podrán decir qué, al definir cuáles son los problemas comunes y cómo serán abordados" (Jelín, 1993). En contraste con las acepciones clásicas y neoliberales, la ciudadanía como equidad aparece estrechamente vinculada con la democracia y la participación en el proceso de toma decisiones y distribución equitativa de recursos económicos y de poder ${ }^{6}$. No obstante, la noción de ciudadanía que priva en la mayoría de los procesos de descentralización local de América Latina y El Caribe es la noción neoliberal; no es casual que dentro del neoliberalismo que presupone el desmonte del Estado de Bienestar Social, la condición de ciudadanía o los derechos civiles no se orienten hacia el Estado, sino que se entienden como la libre expresión de la elección racional y responsable: libertad y responsabilidad son los pilares de dicha condición (Marshall, 1964; Zapata, 1995).

Dentro de la concepción neoliberal, una de las formas propuestas para el logro de la descentralización en América
Latina ha sido la privatización, cuyo objetivo es el de lograr la eficiencia y descargar al Estado-Benefactor de la satisfacción de aquellas demandas que, según la lógica neoliberal, le corresponden al mercado. Coraggio (1994) destaca que los procesos de privatización, en lugar de resolver los problemas planteados por la descentralización, representan una estrategia de los grandes capitales internacionales para "desestatizar" y eliminar las políticas sociales que son funciones propias del Estado; Crozier (1995) por su parte señala que si bien la privatización lleva a reforzar al mercado, este mercado requiere una regulación por parte del Estado. Finalmente, el logro de la eficiencia mediante la reducción de los costos económicos y mediante la privatización y eliminación de los subsidios, pudiera resultar incompatible con la equidad que frecuentemente supone la redistribución de los recursos a través del Estado.

\section{VENEZUELA: ¿DESCENTRALIZACIÓN EFICIEN- TE, PARTICIPATIVA O EQUITATIVA?}

Hasta fines de los años ochenta, la concentración política del poder y la centralización político-administrativa del Estado constituyeron las características definitorias del proceso político venezolano. Junto con la crisis política y económica actual, se produce la deslegitimación del modelo político, el agotamiento del modelo de desarrollo económico, petrolero y rentista, y la emergencia de un tejido organizacional de la sociedad civil cada vez más complejo. Por lo general, este tejido asociativo ha quedado marginado del escenario político a pesar de que la "profundización de la democracia" ha constituido una de las demandas más importantes de parte de los nuevos actores sociopolíticos desde fines de los años setenta.

Dentro de este contexto, la creación de la Comisión para la Reforma del Estado (COPRE) en 1984 y la consiguiente propuesta de descentralización, entendida como la transferencia de competencias y funciones desde el gobierno central hacia los gobiernos estatales y municipales (COPRE, 1988), pretendieron dar respuesta a las demandas de la sociedad civil y a la crisis del proyecto político, fundamentado en el Pacto de Punto Fijo, que se instaura en Venezuela con la Constitución de 1961 (Rey, 1989) ${ }^{7}$. Segun algunos autores (Sonntag, 1997; Urbaneja, 1997), la descentralización coincide con el agotamiento del modelo populista, el cual fue relativamente exitoso políticamente durante varias décadas en América Latina y Venezuela.

5. Nótese que la mayor parte de los proyectos fueron proyectos de acueductos y de salud.

6. La concepción del termino ciudadanía debe entenderse dentro del marco de transformaciones de las sociedad. Si bien en su acepción clásica ciudadanía remite a los privilegios que la condición de "propiedad", en unos casos y la "razón" misma, en otros, conceden al grupo social hegemónico; en la connotación neoliberal, la concepción de ciudadanía aparece vinculada al mercado y distanciada del Estado.

7. Uno de los objetivos de la COPRE fue la democratización del poder para lograr una mayor legitimidad política via el acercamiento entre el gobernante y el gobernado. En este contexto, la descentralización "significa una redistribución territorial del poder... La descentralización remite al doble mecanismo de crear instancias de participación democráticas más extendidas y gobernables, y ser un poderosísimo impulso para descongestionar al Estado y permitir su eficacia" (COPRE, 1988, p. 60). 


\section{Marco constitucional, conflictos legal-institucionales y participación consultiva}

Como consecuencia de la crisis económica y política, el proceso de descentralización en Venezuela se enmarca dentro de un problema de gobernabilidad, a diferencia de Costa Rica, donde algunos analistas señalan la existencia de una "gobernabilidad limitada", y de Brasil y Argentina entre otros países latinoamericanos, donde los procesos de descentralización coincidieron con la transición de los regímenes autoritarios hacia la democracia. En la medida que se acentuaron los problemas económicos y políticos de Venezuela, la falta de gobernabilidad se constituyó en una amenaza a la continuidad del sistema político, tal como se expresó en los dos fallidos golpes de Estado llevados a cabo en el año de 1992 por los militares (García-Guadilla, 1991).

A pesar de estas dificultades de gobernabilidad que se agudizaron con la ruptura de los pactos sociopolíticos que se originaron con los acuerdos de Punto Fijo de 1961 y de la grave crisis económica que impedía la continuidad del Estado-Benefactor, la descentralización en Venezuela no derivó de un proceso de redefinición del marco constitucional tal como ocurrió en Colombia, Brasil, Argentina, Paraguay y otros países de la Región. Ello ha llevado a que en Venezuela existan solapamientos y conflictos legales-institucionales entre la Constitución vigente que data de 1961, las demandas por la democracia participativa de los movimientos sociales de fines de los años setenta y de los años ochenta, y el marco legal producto de la descentralización: la Ley de Descentralización, Delimitación y Transferencia de Competencias del Poder Público (LODDTC, 1989) y la Ley Orgánica del Régimen Municipal (LORM, 1989) resultan incompatibles en algunos aspectos con algunas de las leyes orgánicas de carácter centralista, tales como la Ley Orgánica de Ordenación Urbanística (LOOU, 1989) (García-Guadilla 1997).

Estos conflictos han obstaculizado o retardado la implementación de mecanismos de participación e influencia en el proceso de gestión local que fueron producto de la descentralización. Por ejemplo, la falta de una fundamentación jurídica para la democracia participativa que permitiría, valga la redundancia, la participación de los actores sociopolíticos en los distintos procesos de gestión local junto con la existencia de las leyes orgánicas de corte centralista ya identificadas ${ }^{8}$, dificultan una de las tareas fundamentales encomendadas al Municipio como es la aprobación del Plan de Desarrollo Urbano Local (PDUL), el cual regula las actividades y el uso del suelo, y por ello pudiera constituir un instrumento para facilitar la equidad y eficiencia social ${ }^{9}$.

Los mecanismos de participación formal, instaurados en Venezuela con la descentralización local, son más amplios que los de países de la región tales como Costa Rica, Guatemala y Nicaragua. Sin embargo, estos mecanismos no trascienden más allá de la participación política electoral: en Venezuela se eligen a los alcaldes, los concejales y a los miembros de las parroquias; el alcalde y la mayoría de los concejales se eligen de forma uninominal mientras que los miembros de las juntas parroquiales se eligen por planchas cerradas. Contrariamente a la participación político-electo- ral, la participación de los actores sociales (asociaciones de vecinos) en el proceso de planificación local según la LORM y el Reglamento $\mathrm{N}^{\circ}{ }^{\circ}$, solo incluye participar en la información y en la consulta, dejando fuera la participación en el proceso de distribución y en la gestión de los recursos ${ }^{10}$. Por otro lado, a pesar de las modificaciones a las leyes orgánicas electoral y del régimen municipal que fueron producto de los procesos de Reforma del Estado y de la propia descentralización, es preciso destacar que al no modificarse la "democracia representativa" que se desprende de la Constitución de 1961, la participación dentro de estas leyes no puede trascender el nivel de información y consulta.

\section{Eficiencia económica, eficiencia política, eficiencia social}

En Venezuela, la descentralización se da dentro del contexto neoliberal de la aplicación de medidas económicas de ajuste estructural para enfrentar la crisis económica. Ello ha llevado a que si bien se ha dado un proceso de descentralización política a nivel local, la descentralización administrativa se está dando mayormente como un proceso de desconcentración de funciones y de privatización, lo cual tiene una incidencia negativa en la equidad social ".

De los objetivos explicitados por la COPRE en Venezuela para adoptar la descentralización se desprende que tanto la eficiencia como la participación fueron considerados como relevantes. Sin embargo, a diferencia de Colombia donde se privilegió el objetivo político de reducir los conflictos políticos mediante la participáción, en Venezuela se le dio más importancia al objetivo de la eficiencia del Estado. Debe destacarse, no obstante, que en Venezuela el tema de la eficiencia económica se vincula indirectamente con el de la eficiencia política, ya que al agudizarse la crisis económica, el Estado se vio incapacitado para continuar desempeñando su rol benefactor dentro del capitalismo de Estado prevaleciente en Venezuela perdiendo así legitimidad política.

En lo que respecta a la eficiencia económica, mucho se ha discutido en Venezuela de si la descentralización ha reducido los costos económicos o los ha aumentado. Del estudio del IESA (1997) se desprende que si se compara el monto

8. Por ejemplo, la LOOU resulta frecuentemente incompatible con la LORM en lo que se refiere a las competencias y capacidad de decisión de los actores locales.

9. Es preciso destacar que desde la aprobación de la LORM en 1989 , la cual fue producto de la descentralización, tanto los conflictos entre los distintos actores sociopolíticos que no han logrado negociar sus diferencias como las divergencias entre el nivel local y el nivel central del MINDUR, han impedido que se aprueben los PDUL. Los alcaldes de los municipios con suficiente dinero y experticia técnica que elaboraron un PDUL, lo "engavetaron" antes de confrontarlo en la Cámara Municipal y con los Vecinos ante el miedo que dicha confrontación les restara apoyo político; tal es el caso de Chacao. En otros casos, como en el Municipio Caroní, el PDUL pasó la etapa de la confrontacióm entre los actores pero fue paralizado y no fue aprobado al nivel del Ministerio de Desarrollo Urbano (MINDUR).

10. Ello a pesar de la activa participación que tuvieron las comunidades y movimientos urbanos en la transformación de la LORM y de las demandas por una democracia participativa y por la "profundización de la democracia" (García-Guadilla, 1997).

11. La marginalización del Estado de su papel como redistribuidor de los recursos escasos pudiera conducir a la exclusión cada vez mayor de la población de la prestación de los servicios públicos y sociales. Esto a su vez, aumentaría la conflictividad social. 
relativo de la partida destinada al pago del personal técnico-administrativo de los municipios del país antes y después del inicio de la descentralización, no existen evidencias de que hayan aumentado el número de cargos o los costos correspondientes por este rubro. Por otro lado, algunos municipios como Chacao han logrado aumentar su presupuesto mediante la utilización de mejores sistemas de recaudación de impuestos municipales, lo cual sería indicio de mayor eficiencia. No obstante, resulta difícil hacer generalizaciones sobre la eficiencia económica puesto que en cada municipio se da una situación particular. Estos hallazgos no toman en cuenta que frecuentemente el aumento de los cargos se ha hecho por una vía paralela y de carácter clientelar, creándose fundaciones adscritas a las alcaldías que dependen del ejecutivo o alcalde y que pudieran constituir las nuevas fuentes del clientelismo político; además ha aumentado significativamente el número de municipios, lo que implica el incremento en el número absoluto de cargos.

Por otro lado, la eficiencia política y la gobernabilidad parecen haber aumentado en la mayoría de los municipios con la descentralización ${ }^{12}$. Por ejemplo, la gestión del municipio Chacao, creado en 1992 y enclavado en el Area Metropolitana Interna de Caracas (AMIC) ha sido considerada por los sectores políticos, los medios de comunicación y los propios residentes como una de las más eficaces entre las diferentes experiencias de gobierno local desde que se instauró la LORM y se creó la figura del alcalde electo uninominalmente en 1989 (García-Guadilla et al. 1997). En franca oposición al escenario político nacional caracterizado por la falta de credibilidad y legitimidad del Estado y de los partidos políticos que los representan, la alcaldesa de Chacao fue reelegida en 1995 con el $96 \%$ de los votos y con uno de los niveles mas bajos de abstención de todos los municipios del país, lo que implica un alto nivel de legitimidad que, a su vez, favorece la gobernabilidad en ese municipio. Es preciso destacar que, fundamentándose en este éxito, Irene Saéz se ha lanzado como candidata a la Presidencia de la República para las elecciones de 1998 y en la actualidad, de acuerdo con las encuestas políticas, mantiene un relativamente alto nivel de popularidad entre los candidatos. El elevado nivel de legitimidad de algunos alcaldes se expresa también en la reelección por un segundo periodo o en la elección del partido que representan para un tercer período.

Dado que el poder local reposa en los alcaldes y concejales ${ }^{13}$, el sistema de elección directa producto de la descentralización ha contribuido a reducir la importancia de los partidos políticos en el gobierno local en Venezuela pudiéndose decir que ha mejorado la eficiencia electoral. Además, la elección uninominal de los alcaldes y de la mayor parte de los concejales ha contribuido tambien a otorgarle mayor legitimidad a las autoridades y representantes, y a acercar en mayor grado a los representantes con los representados ${ }^{14}$. Tambien ha servido para otorgar mayor poder a las asociaciones de vecinos (a través de los mecanismos de consulta y referenda especificados dentro del Reglamento No. 1 de la LORM ) facilitando el que estas asociaciones se conviertan en una instancia de seguimiento, control y rendición de cuentas. Sin embargo, del estudio realizado en los municipios Chacao, Baruta, El Hatillo y Libertador del AMIC
(García-Guadilla y Guardía, 1998), se desprende que las asociaciones de vecinos por lo general no utilizan estos mecanismos legales y, además, entre sus demandas no plantean un tipo de participación que trascienda la sancionada por la LORM, la cual, tal como se señaló, es de tipo informativo y consultivo y no contempla la participación para la profundización de la democracia.

Por lo general, la eficiencia económica, o la producción y el mejoramiento de los servicios básicos y sociales, ha estado en función de la capacidad económica del municipio y de sus posibilidades de generar recursos propios. Por otro lado, para evaluar la eficiencia económica vinculada con la producción, costo y calidad de los servicios es preciso que estos servicios y competencias hayan sido transferidos del nivel central a las alcaldías, lo cual depende, a su vez, de que éstas lo soliciten. Debe destacarse que el mayor número de solicitudes de transferencia de competencias (incluyendo los servicios básicos) ha ocurrido en los municipios con mas altos ingresos ${ }^{15}$. Es frecuente que en los municipios con ingresos altos y bajos niveles de pobreza como en Chacao, cuyo tamaño poblacional es pequeño ( 57.000 habitantes) y tiene niveles bajos de marginalidad, se tienda hacia un modelo de gerencia moderna que enfatiza el criterio técnico de eficiencia y calidad en los servicios tales como salud, seguridad y educación ${ }^{16}$.

Otra forma de medir indirectamente la eficiencia es a través del porcentaje que cada alcaldía destina a las partidas de gastos corrientes (incluido el personal), bajo la premisa que cuanto mayor sea este porcentaje, menor será el grado de eficiencia. Usando este indicador indirecto, la eficiencia económica de Chacao es menor que la de otros municipios tales como El Hatillo el cual (al igual que Chacao) tiene también un tamaño pequeño de población (50.086 hab.), un bajo porcentaje de marginalidad y está ubicado en el AMIC. El Hatillo dispone de un presupuesto mucho mas pequeño que Chacao y sin embargo, su porcentaje del presupuesto en gastos corrientes es menor ${ }^{17}$. Esto significa que el logro de la

12. En relación con la forma de resolver las tensiones, algunos autores han destacado que la descentralización ha favorecido la gobernabilidad política (De la Cruz, 1992) y que después del primer intento de golpe militar de febrero de 1992 "la gobernabilidad del sistema tiene mucho que ganar con el proceso de descentralización”.

13. Si bien las Juntas Parroquiales son también instancias del poder local, sus competencias y funciones dependen de aquellas que les asignen el Concejo Municipal.

14. El intento de golpe militar de febrero de 1992 se dirigió al poder nacional puesto que las instancias descentralizadas de las gobernaciones y municipios mantuvieron no solo su legitimidad sino que constituyeron el soporte político ante el vacio dejado por el poder central.

15. No necesariamente los municipios con mayor población son los que tienen mayor ingreso. Por el contrario, el estudio del IESA encontró que con la actual distribución del situado, son los municipios de tamaño mediano los que más se benefician.

16. La evaluación de si este modelo de gerencia moderna que se utiliza en Chacao resulta eficiente desde el punto de vista económico requiere de información sobre los costos de producción de los servicios y no solo sobre la calidad y satisfacción de los usuarios. Puesto que aún no disponemos de información sobre los costos de estos servicios, no podemos llegar a ninguna conclusión.

17. De acuerdo con la alcaldesa del Municipio El Hatillo, Flora Aranguren, ello se debe a "los esfuerzos realizados por lograr la transparencia en la gerencia”. En nuestra opinión, la escasez presupuestaria dificulta el clientelismo y obliga a hacer mas transparente la gestión. 
eficiencia económica no depende exclusivamente de la disponibilidad de recursos económicos, aún cuando éste es un factor condicionante y necesario.

Por otro lado, para lograr la eficiencia política no es suficiente la eficiencia electoral ni la disponibilidad de recursos económicos, ni siquiera el logro de la eficiencia económica, aún cuando estos dos factores son condición necesaria. La eficiencia política, o la capacidad de dar respuesta a las demandas, depende también del estilo (técnico, político o mixto) que se adopte para la gestión, y de los mecanismos (participativos o no) que se instrumenten para reconocer las demandas, y de la eliminación de prácticas clientelares que beneficien a un grupo por encima de los demás. La utilización de procedimientos técnicos y participativos, bien sea para conocer las demandas (a través de encuestas por ejemplo) o para distribuir los recursos a los grupos de la población que mas lo necesitan, tiende a aumentar la eficiencia política aún cuando puede reducir la eficiencia económica al aumentar los costos.

La utilización combinada de mecanismos técnico-políticos (García-Guadilla et al., 1997) ha llevado al municipio Chacao a un relativamente alto grado de eficiencia política a juzgar, no solo por la reelección de su alcaldesa, sino también por los altos niveles de satisfacción de los residentes. La razón de este éxito político se debe a la aplicación de un modelo mixto: a) de carácter técnico-gerencial en la relación con los comerciantes, los empresarios y la clase media residente del municipio y b) de carácter político y "clientelar" para responder las demandas de los escasos residentes de los barrios pobres ${ }^{18}$. Por otra parte, el Municipio Chacao ha incorporado algunos elementos técnico-participativos en lo que respecta fundamentalmente a la elaboración del presupuesto donde se consulta a las asociaciones de vecinos para la elaboración de las inversiones prioritarias; también se aplican procedimientos técnicos para dar seguimiento a las demandas o quejas a través de la Oficina de Atención a la Comunidad.

Otro de los municipios que podría considerarse eficiente desde el punto de vista político es el Municipio Caroní que corresponde a Ciudad Guayana, ubicada en el Estado Bolívar. En este municipio, el cual alberga a más de 500.000 personas y donde existen elevados niveles de pobreza, desde el inicio de la gestión del partido de izquierda La Causa $\mathrm{R}$ en 1990, se utilizaron mecanismos participativos con bastante éxito para definir la identidad de las parroquias y elaborar el presupuesto (Harneker, 1994; Gónzalez de Pacheco, 1998). La medida del éxito político se refleja en la elección por tres períodos consecutivos de los candidatos del partido La Causa $\mathrm{R}$ y en el logro de consenso entre los diferentes actores sociopolíticos locales para la elaboración y aprobación del PDUL ${ }^{19}$. Además de estos mecanismos de participación, otros factores que incidieron en la eficiencia política fueron la existencia de un presupuesto relativamente holgado como consecuencia de que el Municipio Caroní es la sede de la industria básica del Estado, la figura carismática del alcalde y la vinculación entre la Causa $\mathrm{R}$ y el movimiento sindical de estas industrias básicas ${ }^{20}$. De hecho, el partido de la Causa $\mathrm{R}$ no logró esta alta eficiencia política en el Municipio Libertador durante el periodo 1992-1995. El municipio Libertador, el cual está ubicado en el AMIC, es uno de los de mayor población de Venezuela (1.823.222 hab.) y, al igual que en el municipio Caroní, los porcentajes de pobreza superan el $50 \%$ de la población total. Si bien las elecciones de 1992 para alcalde fueron ganadas por un candidato de la Causa $\mathrm{R}$ con alto carisma personal, éste no fue relegido para un segundo lapso a pesar de los intentos de aplicar criterios técnicos para resolver las múltiples demandas de la población residente y que la participación y creación de instancias participativas como las parroquias constituyeron objetivos prioritarios de la gestión. Puesto que una de las diferencias entre el municipio Caroní y Libertador es la cuantía de recursos económicos disponibles, pudiera concluírse que ni la aplicación de criterios técnicos ni la inclusión de la participación aseguran la eficiencia política si no se cuentan con suficientes recursos presupuestarios para satisfacer las demandas de una población mayoritariamente pobre.

\section{3. ¿Continuidad o ruptura de la cultura política?: la equidad y ciudadanía}

El poder otorgado a las asociaciones de vecinos mediante el Reglamento No. 1 de la LORM, que fue producto de la descentralización y demandas de las organizaciones sociales, ha llevado a los partidos políticos a intentos exitosos de cooptación del movimiento vecinal, sobre todo en los barrios pobres. Por otro lado, las prácticas clientelares que en el pasado se observaban en la relación elector-partido político, en la actualidad tienden a darse entre algunas asociaciones de vecinos y el alcalde y concejales. El hecho que a pesar de la descentralización, las juntas parroquiales sean elegidas por planchas cerradas, ha llevado a que sean los partidos políticos tradicionales quienes las controlan y que en estos espacios las relaciones clientelares elector-partido continúen teniendo vigencia.

Puesto que la descentralización se plantea como objetivo la eficiencia, una consecuencia debería ser la trans-

18. Pudiera pensarse que la utilización de criterios políticos en lugar de téenicos, y de un estilo clientelar y particularista en lugar de universalista para satisfacer las demandas de la población reduce la eficiencia política al concentrar los recursos escasos en un grupo. No obstante, esta afirmación parece ser cierta solo en aquellos municipios que tienen escasez de recursos limitados (situación mas frecuente); en caso de holgura presupuestaria (como en Chacao), la utilización mixta de criterios técnicos y políticos, e incluso clientelares, para distribuir el presupuesto pudiera haber contribuido a aumentar la legitimidad de la alcaldesa entre los sectores pobres del municipio. Ello es debido a que la bonanza de recursos garantiza que dicha distribución no se haga a expensas de los otros grupos de la población del municipio quienes tambien pueden ver satisfechas sus demandas.

19. A pesar de existir concenso local alrededor del PDUL, éste no fue aprobado por el nivel central del Ministerio de Desarrollo Urbano (MINDUR) en un claro ejemplo de conflicto entre las competencias y concepciones sobre la participación entre el nivel central y local.

20. Si bien en el Municipio Caroní se obtuvo mayor eficiencia política, no se ha logrado el mismo éxito que en el Municipio de Porto Alegre, Brasil, donde un gobierno de tendencia tambien izquierdista, el cual aplicó estrategias semejantes, logró mayor legitimidad via los presupuestos participativos (Harneker, 1993). Ello se debe en parte a la incapacidad del gobierno local del Municipio Caroní para responder a las demandas que trascienden ese nivel, como lo es el caso de la tenencia de la tierra, y que, por consiguiente, deben ser negociadas con actores extralocales. 
formación de la cultura política, particularista y clientelar, hacia una cultura de carácter universalista en lo que respecta a la relación entre gobernantes y ciudadanos. Los estudios realizados por García-Guadilla $(1997,1998)$ en los municipios de Chacao, El Hatillo y Baruta demuestran que, si bien las prácticas clientelares de carácter individual tienden a reducirse como consecuencia de la uninominalidad de los representantes electos, estas prácticas reaparecen en las asociaciones de vecinos y su relación con los concejales y el alcalde ${ }^{21}$.

En lo que se refiere a la eficiencia social, ésta requiere de la existencia de la eficiencia económica y política aún cuando éstos no son factores suficientes para garantizarla. En aquellos municipios donde existe un alto porcentaje de pobreza, la eficiencia social está en función de factores tales como la existencia de recursos suficientes para responder a las demandas básicas y la participación para decidir la distribución equitativa de dichos recursos (económicos y de poder) entre todos los grupos de la población. De hecho, a pesar que tanto en el municipio Caroní como Libertador supuestamente se definieron criterios de participación y equidad para distribuir los recursos, en ninguno se logró la equidad o eficiencia social por no existir una concepción de "ciudadanía" que incluyera la participación de los actores sociales en el proceso de decisión o alocación de dichos recursos. No obstante, la eficiencia política fue mayor en Caroní debido, en parte, a la existencia de un mayor presupuesto para satisfacer las demandas. En municipios con porcentajes relativamente menores de pobreza, como en Chacao, la holgura de recursos facilita la utilización del criterio de equidad en la distribución de los recursos y contribuye además a la eficiencia política y a la legitimidad. La existencia de recursos disponibles le da posibilidad al gobierno local de incidir en la producción y calidad de los servicios así como tambien el decidir los costos, tarifas y distribución de éstos. En los municipios pobres, estas decisiones se mantienen en el nivel central y no existe la posibilidad de que el gobierno local participe. Adicionalmente, muchas de las demandas de la población en los municipios pobres, tales como la propiedad de la tierra ocupada, trascienden tambien el nivel local y por lo tanto no pueden negociarse.

A pesar que los mecanismos de participación de la comunidad son mas amplios en Venezuela que en la mayoría de los países de la región (con la excepción de Colombia), se observa que la concepción de participación no incorpora una noción de ciudadanía que avance la democracia participativa. Los mecanismos legales existentes se limitan a la participación consultiva y el proceso de toma de decisiones se concentra en el Concejo Municipal e incluso, trasciende al nivel central.

Los estudios realizados en los municipios de Chacao, Baruta y El Hatillo (García-Guadilla y Guardia, 1998) acerca de la concepción que los actores políticos tienen del concepto de "ciudadanía" indican que este término connota prioritariamente "deberes cívicos de los ciudadanos" y una ciudadanía político-electoral, en lugar de derechos para participar en el proceso de decidir acerca de la distribución de los recursos. Quizás ésta sea la explicación sobre la falta de conflicto que existe alrededor de la participación en las decisiones puesto que, hasta el momento, este tipo de participación no constituye una demanda movilizadora de las asociaciones de vecinos o de la sociedad civil organizada. En síntesis, no se demanda una democracia participativa sino el perfeccionamiento de la democracia representativa porque no ha habido un verdadero cambio en la cultura política a pesar de la descentralización.

\section{ALGUNAS CONSIDERACIONES FINALES}

Uno de los logros mas importantes de la descentralización en Venezuela ha sido la descentralización política a nivel local y con ello, la mayor eficiencia electoral y legitimación de los gobiernos locales en un momento de pérdida de legitimidad y crisis política del gobierno y partidos políticos del nivel central. No obstante, uno de los obstáculos mayores a dicho proceso ha sido la falta de una verdadera descentralización económica, lo cual ha dificultado la autonomía de las instancias locales en el proceso de distribuir recursos a nivel local para satisfacer las demandas de la población dado que parece existir una asociación directa entre la mayor disponibilidad de recursos económicos, una mayor legitimidad política y la capacidad para atender las demandas o la eficiencia social.

A pesar del logro de la eficiencia electoral y su impacto en el mejoramiento de la eficiencia política y legitimidad de los representantes locales electos, la descentralización no ha logrado aún garantizar la eficiencia social o equidad, sobre todo en los municipios mas pobres. De hecho, la mayor legitimidad y aceptación de los gobernantes locales no parece depender de prácticas "eficientes" desde el punto de vista económico del gobierno local, ni del estilo gerencial o clientelar, ni del modelo técnico o político que se instrumente. Por el contrario, el factor mas relevante que explica la legitimidad y éxito parece ser "la disponibilidad y capacidad de generar recursos económicos" que tiene el municipio, lo cual permite atender las demandas de la mayoría de la población. Una vez que existen recursos suficientes para atender las demandas, los demás factores tales como el estilo de gestión, las prácticas particularistas o universalistas, la concepción de ciudadanía y la importancia que se le asigna a la democracia participativa, se constituyen en la clave para explicar las diferencias en la eficiencia económica, política y social de los municipios.

La aprobación del PDUL, como instrumento que facilite la gobernabilidad local es decir, que viabilice las demandas y asegure las relaciones entre los distintos actores locales dentro de un marco de democracia participativa requiere de un cambio de la cultura política que lleve a los actores a demandar "efectivamente" la participación en el proceso de toma de decisiones es decir, a proponer demandas de ciudadanía popular. La descentralización, hasta el momento, no ha sido consecuencia del cambio de la cultura política

21 El hecho que dichas asociaciones de vecinos tengan poder consultivo en el gobierno local, y en ocasiones sean cooptadas por los partidos políticos, lleva a que algunas asociaciones de vecinos desarrollen nuevas formas de clientelismo ligadas a estas formas asociativas. 
aún cuando pudiera estar estimulándolo; en este sentido, las demandas por la profundización de la democracia parecen ser mas un mito u objetivo a lograr de los estudiosos de la participación que una realidad.

Por otro lado, la falta de una descentralización económica y el énfasis en la privatización de los servicios como una forma de generar y recuperar recursos económicos para mejorar la calidad de los servicios a nivel municipal, dificultan el logro de la eficiencia social o equidad, sobre todo en los muncipios pobres. Sin embargo, no significa que la eficiencia económica, política y social sean antagónicas; por el contrario, estas tres dimensiones de la descentralización son condición necesaria para la profundización de la democracia y el cambio en la relación Estado-sociedad civil. Para garantizar la equidad que fundamente la gobernabilidad democrática, además de la eficiencia económica y política se requiere de la existencia de una concepción de ciudadanía que privilegie el "derecho a tener derechos" o el derecho que tienen todos los actores sociopolíticos a participar en la distribución y toma de decisiones alrededor de los recursos escasos, sean éstos económicos o de poder. En síntesis, las tres dimensiones deben representar los puntos de un continuum cuyo objetivo último es la profundización de la democracia.

\section{REFERENCIAS BIBLIOGRÁFICAS Y DOCUMENTALES}

BORJA, Jordi (1988): “Descentralización: una cuestión de método”. Estado y Ciudad. J. Borja. PPU.

BRISCOE, John. and David de Ferranti (1988): "Water for Rural Communities: Helping People Help Themselves". Washington, D.C.: World Bank.

Campbell, Tim with George Petersen and Jose Brakarz (1991): Decentralization to Local Government in LAC: Nacional Strategies and Local Response in Planning, spending and Management. Latin America and the Caribbean Technical Department. Report. No. 5. The World Bank.

COPRE, Comisión Presidencial para la Reforma del ESTADO (1988): La Reforma del Estado. Vol. 1. Caracas, Venezuela.

Coraggio, José Luis (1994): "Las dos corrientes de la descentralización en América Latina”. Gobierno Regional y Municipal. Año 1, Núm. 6. Editorial Jurídica Conosur LTDA.

CóRDOva Macias, Ricardo y Ortega Hegg, Manuel (1996): Centroamérica: Gobierno local y participación ciudadana. Nicaragua. FLACSO Programa El Salvador, San Salvador:

Crozier, Michel (1995): "La posición del estado ante los otros actores". Revista Gestión y Análisis de Políticas Públicas. No. 2.

Cunill, Nuria (1997): Repensando lo puíblico a través de la sociedad: nuevas formas de gestión pública y representación social. Caracas. CLAD-Editorial Nueva Sociedad.

De LA CruZ, Rafael (1992): "La estrategia de la descentralización en Venezuela”. En Rafael de la Cruz (Coord.) Descentralización, gobernabilidad y democracia. COPRE/PNUD/Editorial Nueva Sociedad. Caracas, Venezuela.
Diario El NACiOnal (1992-1997): Caracas.

DiARIO El UNIVERSAL (1992-1997): Caracas.

Finsterbush, Kurt y Warren Van Wicklin III (1987): "Contribution of Beneficiary Participation to Development Project Effectiveness". Public Administration and Development 7 (January-March):1-23

García-Guadilla, María Pilar e Inés Guardía (1998): "Participación y concepciones de ciudadanía de los nuevos actores sociopolíticos locales: el caso venezolano". XXI Encuentro RNIU sobre Ciudadanía y Gestión Democrática. Yucatán, México.

García-Guadilla, María Pilar (1998): "Democracia, descentralización y clientelismos: nuevos actores y viejas prácticas políticas”. DIGIBIS, Publicaciones Digitales. 49avo Congreso Internacional de Americanistas. Quito, Ecuador:

García Guadilla, María Pilar; Roa, Ernesto; y Rodríguez, Juan Carlos (1997): "Modelo de Gestión, Gobernabilidad y Participación: el Municipio Chacao, Venezuela". en Manuel Alcantára (Ed.): América Latina Realidades y Perspectivas. Estudios Científicos, Universidad de Salamanca. pp. 47-84.

GarCía-GuadILla, María Pilar (1997): "Desdemocratización, descentralización local y participación social en Venezuela: Obstáculos y oportunidades”. II Reunión de la Red Nacional de Investigaciones Urbanas. México, Tlaxcala.

GarCíA-GuAdilla, María Pilar (1991): "Crisis, actores y conflictos sociopolíticos en la Venezuela post-saudita: encrucijada de la democracia". Argos No. 14, Caracas.

GarCía-Guadilla, María Pilar (1988): "La participación de la sociedad civil en la Planificación Urbana”. Primeras Jornadas sobre Planificación de Ciudadades Medianas. MINDUR-INTEPLAN. Mimeo.

GonzÁlez de PACHeCo, Rosa Amelia (1998): "Democratización a nivel local: el caso de la formulación participativa del presupuesto del Municipio Caroní". Manuscrito. Universidad Simón Bolívar.

HARNEKER, Marta (1994): Alcaldia de Caroni. Gobernar: tarea de todos. Caracas: Fundarte - Alcaldía de Caracas, Dirección de Imprenta Municipal.

HarneKer, Marta (1993): Alcaldía de Porto Alegre. Aprendiendo a gobernar. La Habana: Mepla - Alcaldía de Durango, México.

HeREDIA, Blanca (1997): "Clientelism in Flux: Democratization and Interest Intermediation in Contemporary Mexico”. Paper presented at the XXth International Congress of the Latin American Studies Association (LASA). Guadalajara, México, abril.

IESA, Instituto de Estudios Superiores de Administración (1997): Federalismo Fiscal y descentralización: una nueva relación entre la sociedad y el Estado. Rafael de la Cruz y col. Caracas.

IsHAM, Jonathan; Deepa Narayan, y Lant Pritchett (1995): "Does participation improve performance? Establishing Causality with Subjective Data”. The International Bank for Reconstruction and Development. The World Bank.

Jelín, Elizabeth (1993): “¿Cómo construir ciudadanía?: una visión desde abajo". European Review of Latin American and Caribbean Studies 55, pp. 21-37. 
Korten, David C. (1980): "Community Organitation and Rural Development: A learning Process Approach”. Public Administration Review 40 (5, September-October):480-510.

NARAYAn, Deepa (1995): “The Contribution of People's Participation: Evidence from 121 Rural Water Supply Projects" ESD Occasional Paper Series 1. World Bank, Environmentally Sustainable Development Department, Washington, D.C.

Marshall, T. H. (1964): Class, Citizenship and social Development. Doubleday \& Co. New York.

Ortega Hegg, Manuel (1997): La descentralización del Estado de Nicaragua. Documentos CASC-UCA.

REPÚBLICA dE VENEZUela (1989): Ley Orgánica del Regimen Municipal. Caracas.

República de Venezuela (1989): Ley Orgánica de Ordenación Urbanística. Caracas.

República de Venezuela (1990): Reglamento Parcial No. 1. de la Ley Orgánica del Regimen Municipal sobre Participación de la Comunidad. Caracas.
RESTREPO, Dario (1997): "Eslabones y precipicios entre la participación y la democracia”. Seminario: La participación ciudadana en el marco del fortalecimiento de la democracia. Caracas, Venezuela.

REY, Juan Carlos (1987): "El futuro de la democracia en Venezuela" en El futuro de la democracia en Venezuela. IDEA, Caracas.

SonntaG, Heinz (1997): Cátedra: Descentralización y el Futuro de la Democracia. Centro Latinoamericano Rómulo Gallegos (CELARG), Caracas.

UNDP (United Development Programme) (1993): The Human Development Report 1993. New York: Oxford University Press.

Urbaneja, Diego Bautista. (1997): Cátedra: Descentralización y el Futuro de la Democracia. Centro Latinoamericano Rómulo Gallegos (CELARG), Caracas, junio.

WORLD BANK (1991) World Development Report (1991): New York: Oxford University Press.

ZAPATA Barrero, Richard (1995): "Hacia una teoría normativa de la ciüdadanía democrática”, en Leviatán. Revista de Hechos e Ideas, No. 59, Madrid.

\section{RESUMEN}

La descentralización es uno de los mecanismos mediante el cual el Estado central transfiere competencias políticas y administrativas a las localidades, ya sea con la finalidad de fortalecer la participación política, lograr eficiencia estatal o para buscar la gobernabilidad. En algunos países latinoamericanos como Colombia, Chile, Argentina, Brasil, Costa Rica se han impulado procesos de descentralización con el fin de racionalizar la actividad estatal y, precisamente, contribuir a la gobernabilidad.

En Venezuela la Comisión para la Reforma del Estado (COPRE) implementó la descentralización en 1988 como una forma de superar el modelo estado céntrico, caracterísitico de las últimas décadas en el país. El proceso no estuvo acompañado por cambios constitucionales, lo que condujo a conflictos entre diversas normas y al consiguiente retraso en la implementación de las nuevas políticas. El ejercicio descentralizador se está desarrollando principalmente a nivel político, por ejemplo, en los municipios de Chacao, Baruta, El Hatillo y Libertador, que pertenecen al Area Metropolitana Interna de Caracas. Así, el proceso descentralizador se vive con diferencias marcadas resultantes del tipo de administración implementada desde la alcaldía, la mayor o menor disponibilidad de resursos económicos y humanos, la población y la pobreza.

Palabras clave: Descentralización, eficiencia, eficacia, equidad, participación, gobernabilidad, ciudadanía

\section{ABSTRACT}

Decentralization is one of the mechanisms by which the central State transfers political and administrative competences to the localities, sometimes with the purpose of strenghtening political participation, to achieve state efficiency of to look for gobernability. In some Latin American countries such as Colombia, Chile, Argentina, Brasil, Costa Rica have been decentralization processes impulsed to rationalize the public activity and, precisely, to contribute to gobernability.

In Venezuela the Comission for the State Reform (COPRE) implemented the decentralization in 1988 as a way of excelling the centric state model, characteristic of the last decades in the country. This process was not acompanied by constitutional changes, what drived to conflicts between several norms and the consequent delay of the new policies implementation. The decentralization is being developed mainly at the political level, for example, in the Chacao, Baruta, El Hatillo and Libertador municipalities, which belong to the Intern Metropolitan Area of Caracas. So, the decentralization process is lived with pronounced differences as a result of the kind of administration implemented from the mayoralty, the high or less availability of human and economic resources, the population and the poverty.

Key words: Decentralization, Efficiency, Efficacy, Equity, Participation, Gobernability, Citizenship. 


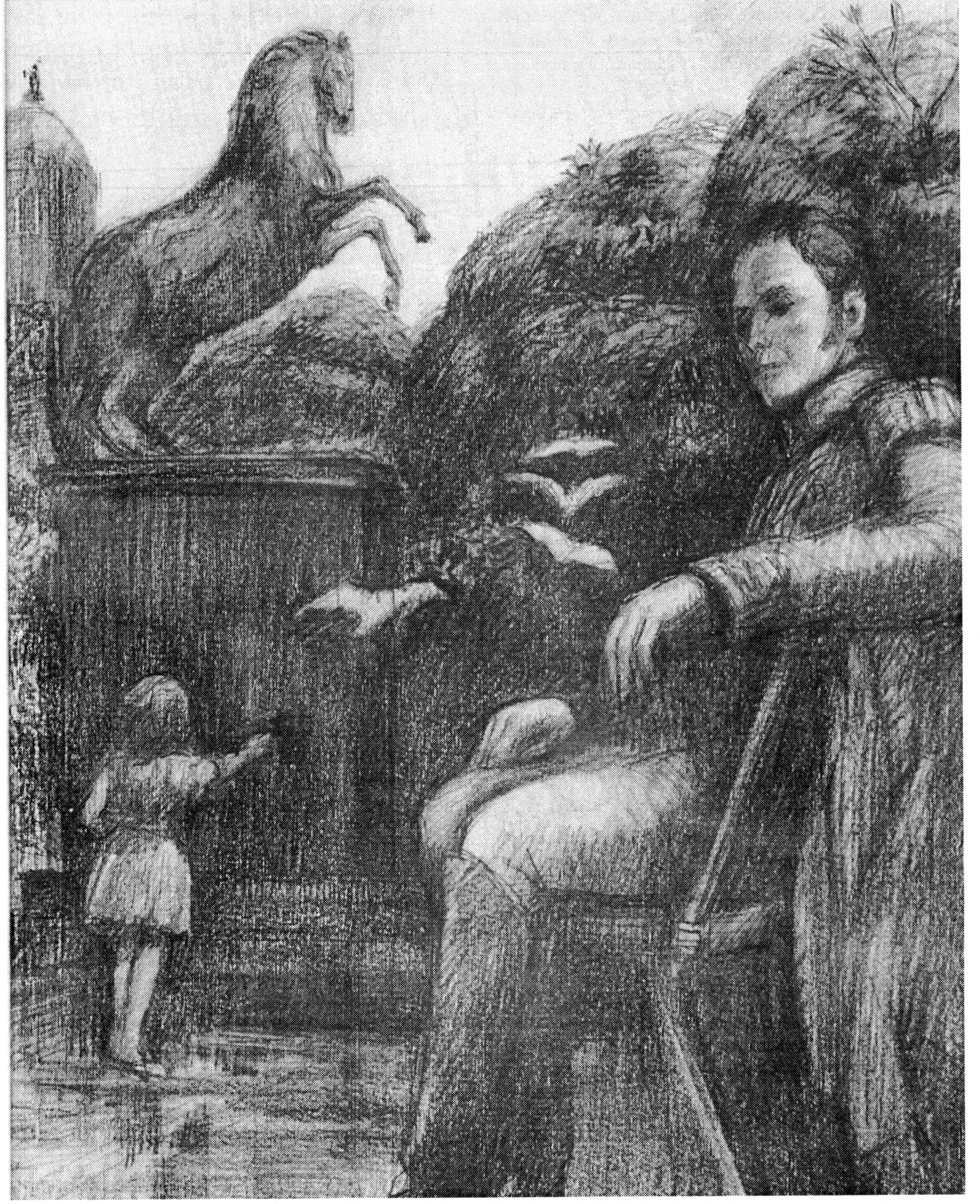

Jacobo Borges y Luis Guevara Moreno 